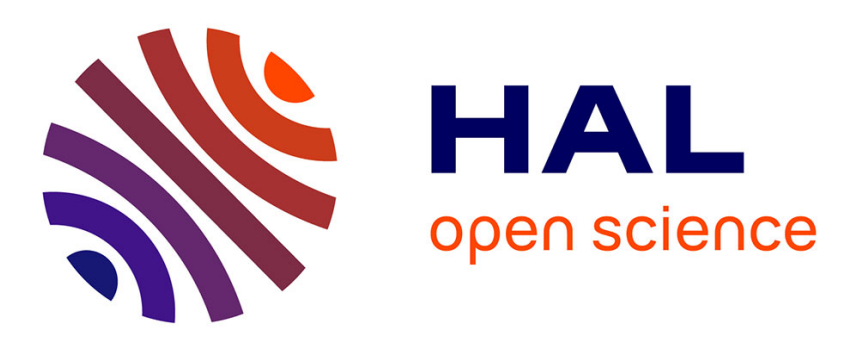

\title{
Stochastic Overall Equipment Effectiveness
}

Francesco Aldo Zammori, Marcello Braglia, Marco Frosolini

\section{To cite this version:}

Francesco Aldo Zammori, Marcello Braglia, Marco Frosolini. Stochastic Overall Equipment Effectiveness. International Journal of Production Research, 2011, pp.1. 10.1080/00207543.2010.519358 . hal-00665447

\section{HAL Id: hal-00665447 \\ https://hal.science/hal-00665447}

Submitted on 2 Feb 2012

HAL is a multi-disciplinary open access archive for the deposit and dissemination of scientific research documents, whether they are published or not. The documents may come from teaching and research institutions in France or abroad, or from public or private research centers.
L'archive ouverte pluridisciplinaire HAL, est destinée au dépôt et à la diffusion de documents scientifiques de niveau recherche, publiés ou non, émanant des établissements d'enseignement et de recherche français ou étrangers, des laboratoires publics ou privés. 


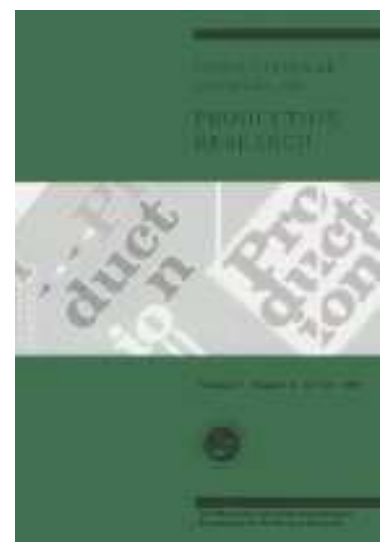

\section{Stochastic Overall Equipment Effectiveness}

\begin{tabular}{|r|l|}
\hline Journal: & International Journal of Production Research \\
\hline Manuscript ID: & TPRS-2010-IJPR-0336.R1 \\
\hline Manuscript Type: & Original Manuscript \\
\hline Date Submitted by the \\
Author: & 19 -Jul-2010 \\
\hline Complete List of Authors: & $\begin{array}{l}\text { Zammori, Francesco; Università di Pisa, Mechanical Nuclear and } \\
\text { Production Engineering } \\
\text { Braglia, Marcello; Università di Pisa } \\
\text { Frosolini, Marco; Università di Pisa }\end{array}$ \\
\hline Keywords: & $\begin{array}{l}\text { LEAN MANUFACTURING, PERFORMANCE ANALYSIS, STATISTICAL } \\
\text { METHODS }\end{array}$ \\
\hline Keywords (user): & Overall Equipment Effectiveness \\
\hline &
\end{tabular}

\section{SCHOLARONE Manuscripts}




\title{
STOCHASTIC OVERALL EQUIPMENT EFFECTIVENESS
}

\author{
Francesco Zammori*, Marcello Braglia, Marco Frosolini \\ Dipartimento di Ingegneria Meccanica, Nucleare e della Produzione, \\ Università di Pisa \\ Via Bonanno Pisano, 25/B - 56126 PISA (Italy)
}

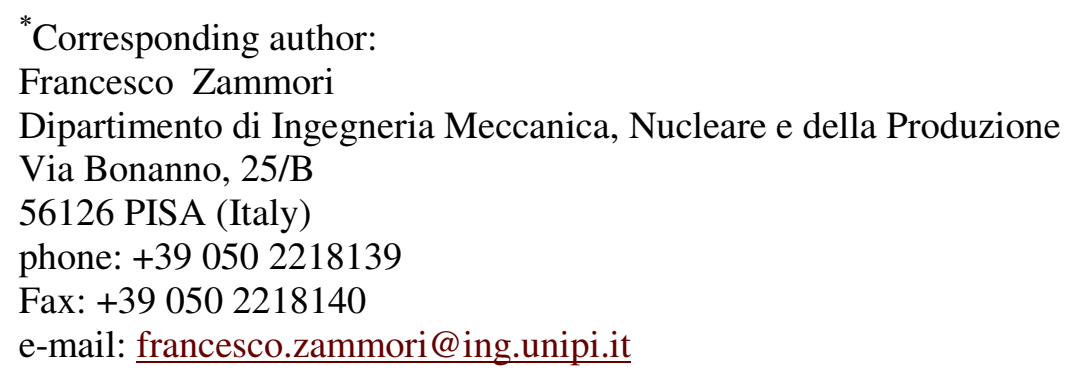




\title{
Stochastic Overall Equipment Effectiveness
}

\author{
Abstract's number of words $=196$; \\ Manuscript's number of words $=6200$;
}

\begin{abstract}
This paper focuses on the Overall Equipment Effectiveness (OEE), a key performance indicator typically adopted to support Lean Manufacturing and Total Productive Maintenance. Unfortunately, being a deterministic metric, the OEE only provides a static representation of a process, but fails to capture the real variability of manufacturing performances. To take into account the stochastic nature of the OEE, an approximated procedure based on the application of the Central Limit Theorem is presented: the $\mathrm{OEE}$ is considered as a stochastic random variable and its probability density function (pdf) is generated through the aggregation of the pdf of the basic causes of waste. Notwithstanding its approximated nature, the procedure can be applied in most practical cases, since the accuracy is assured provided that the average OEE is lower than $90 \%$ and the variability of the losses is high. The validity of the approach has been also confirmed by an industrial application included in the paper. Obtained results demonstrate that the Stochastic OEE can help in battling variation, for it allows to identify the hidden losses that account for most of the variability and to estimate the impacts of potential corrective actions in terms of both efficiency and efficacy.
\end{abstract}

Key Words: Lean Manufacturing; Overall Equipment Effectiveness; Performance Analysis; Statistical Methods;

\section{Nomenclature}

- A = Availability;

- $\mathrm{CT}=$ Cycle Time

- DF $=$ Number of Defects

- $\quad$ DT $=$ Down Time

- $\mathrm{G}_{1}=$ Time Gap between the Opening Time and the Net Loading Time

- $\mathrm{G}_{2}=$ Time Gap between the Net Loading Time and the Valuable Time

- $\quad$ LT = Loading Time 
- $\quad$ MI = Number of Manufactured Items

- $\quad$ NLT $=$ Net Loading Time

- $\quad$ NOpT $=$ Net Operating Time

- $\mathrm{NU}=$ Net Utilization;

- OEE = Overall Equipment Effectiveness

- OpE = Operation Effectiveness

- OpT = Operating Time

- $\mathrm{OT}=$ Opening Time

- PLT = Time wasted due to Performance Losses

- $\mathrm{P}=$ Performance Rate

- $\mathrm{Q}=$ Quality Rate;

- QRT = Time wasted due to Quality Rate

- $\mathrm{SBT}=$ Stand By Time

- $\quad \mathrm{TT}=$ Theoretical Time

- VT = Valuable Time

\section{Introduction}

Lean Manufacturing is a managerial approach based on Toyota Production System, which is intended to create value for the customers by meeting their needs and expectations in a better way (Shingo, 1981; Ohno, 1988). To this aim Lean Manufacturing strains for perfection, in order to develop an ideal manufacturing process characterized by a leveled flow pull by customer's demand, where all the activities that contribute zero value for the customers have been removed. Recently, this concept has been extended, under the name of Lean Thinking, to encompass all the processes performed by a company (Hines et al., 2004; Dhandapani et al., 2004), but even in this case waste removal at the shop-floor level remains the basic step that must be accomplished before Lean Thinking can evolve toward a holistic and strategic level (Braglia et al., 2009).

As a matter of fact, several operating techniques, derived from the industrial engineering field, have been proposed in technical literature to spot and remove inefficiencies and hidden losses (see for example Hines and Rich, 1997; Emiliani, 2000; McDonald et al., 2002; Braglia et al., 2006; Braglia et al., 2009). 
Among the several lean tools proposed in literature, this paper focuses on the Overall Equipment Effectiveness (OEE), a well known efficiency metric that allows evaluating the impact of several hidden losses, by comparing the actual performance of an equipment with respect to its theoretical potential (Jonsson and Lesshammar, 1999). The OEE was firstly proposed by Nakajima (1988) as the key performance indicator to support Total Productive Maintenance and is computed as follows (Ljungberg, 1998):

$$
\text { OEE }=\text { Availability } \times \text { Performance Rate } \times \text { Quality Rate }
$$

where:

- Availability (A) is a comparison between the amount of time a machine is actually producing and the amount of time it was scheduled to produce;

- Performance Rate $(\mathrm{P})$ is a comparison between the real production of a machine and the expected production for the same time;

- Quality Rate $(\mathrm{Q})$ is the fraction of produced items that fit specifications.

Nowadays, the OEE is a widely accepted way to monitor the actual performance of an equipment, in relation to its nominal capabilities under optimal operating conditions (SEMI, 1996). Nevertheless, the computation of the OEE is not always straightforward and many drawbacks and difficulties can still be found in many industrial applications (Bulent et al., 2000, Jeong and Phillips, 2001; Gouvêa and Pinheiro, 2002; De Ron and Rooda, 2005-2006, Braglia et al. 2008).

Problems typically arise while collecting the data required for the analysis and/or when it is necessary to adapt the losses classification structure of the OEE to fit the requirements of a specific industry. To overcome these problems, many interesting solutions have been proposed and a comprehensive literature review can be found in the recent work of Muchiri and Pintelon (2007).

Unfortunately, a practical problem that has not been solved yet concerns the definition of the data collection period. No frameworks are available to support this choice, and practitioners make use of rules of thumb, such as the adoption of the working cycle of the factory, (i.e. one, two or three shifts) as the standard time frame for the OEE computation. Anyway, this simple approach is not always satisfactory, as clearly demonstrated by Figure 1, which shows the different trend of the OEE evaluated over two different time horizons (of one and five working days, respectively). As can be seen, due to the day to day variability of the manufacturing performances, the daily 
value of the OEE tends to be excessively uneven and it is hard to evaluate the real efficiency of an equipment and to define sensible improvement targets.

Take in 'Fig. 1' about here

Conversely, if one takes a monthly or quarterly time frame, the observed OEE converges to an average value and the information concerning its variability (which directly reflects the variability of the whole manufacturing process) gets lost. This is a main weakness of the standard approach, because variability is one of the main causes of waste and must be carefully analyzed and reduced, before Lean Manufacturing can be set into place (George, 2002, Braglia et al., 2009). As a matter of fact, variability affects work in process and queuing time, causes congestion and makes uncertain the processing time. In addition, it tends to propagate and to amplify, by impacting on the arrival and departure rates of materials from one machine to the next one, with the consequence of delays and losses of production capacity (Hopp and Spearman, 2000).

Considering these issues, it seems advisable to include variability analysis in the OEE computation. To this aim the OEE is treated as a stochastic random variable and an approximated statistical approach is used to generate its pdf, starting from the pdf of the main determinants of waste. In this way one can easily evaluate the mean and the standard deviation (i.e. the variability) of the OEE, and even the choice of an effective data collection period can be greatly simplified. For example, the previously mentioned approaches could be combined in an effective way: whereas the working cycle of the factory can be taken as the appropriate data collection period, a monthly/quarterly time frame can be used to aggregate data to generate the pdf of the OEE. This assures the consistency and the robustness of the obtained results, without losing and/or compromising the valuable information concerning the variability of the manufacturing performance.

Another advantage offered by the proposed methodology is the possibility to identify the hidden losses that account for most of the observed variability, and to compare the impact of alternative corrective actions in terms of efficiency and efficacy. Generally speaking, a manufacturing process is said to be effective if it has the capacity to obtain the desired results and is said to be efficient if its outputs are obtained with the minimum amount of resources/inputs. In other words, efficacy focuses on the outputs 
and expresses whether a process works or not; efficiency focuses on the inputs and expresses how well a process works.

In the present case, since we are considering the effect of a corrective action, the expected result is the reduction of time that is lost in unproductive activities. Therefore, whether the solution works or not (i.e. its capability to produce the desired results) and how well it works can be evaluated through the stability and through the increment of the obtained operating time, respectively. In this sense, one can estimate the modification of the pdf of the OEE that would be induced by the deployment of a corrective action and can assess the efficiency and the efficacy of the corrective action itself, in terms of reduction of the average and of the standard deviation of the OEE.

\section{The OEE losses classification structure}

Any effectiveness indicator $E$ can be defined as the ratio between what was actually manufactured and what could have been ideally manufactured or, alternatively, as the fraction of time in which an equipment works at its full operating capacity. This concept can be analytically expressed as follows:

$$
\begin{aligned}
& E=\frac{\text { Actual Output }}{\text { Theoretical Output }}= \\
& \qquad=\frac{\text { Cycle Time } \times \text { Valuable Time }}{\text { Cycle Time } \times \text { Theoretical Time }}=\frac{\text { Valuable Time }}{\text { Theoretical Time }}
\end{aligned}
$$

where the Valuable Time is the portion of time in which an equipment works under optimal operating conditions and the Theoretical Time is the maximum interval of time that is ideally available for production.

Take in 'Fig. 2' about here

As shown in Figure 2, the gap between the Theoretical Time and the Valuable Time can be explained as the consequence of many causes of inefficiency (i.e. hidden losses) which progressively erode the fraction of time in which an equipment can works at its nominal capability. In other words, due to planned and unplanned stops, only a portion of the Theoretical Time can be used for manufacturing.

Starting from the losses classification structure of Figure 2, one can easily define three effectiveness metrics using different quantities as Theoretical Time in equation (2): 
Net Utilization $(N U)=\frac{\text { Valuable Time }}{\text { Opening Time }}$

$$
\text { Operation Effectiveness }(O p E)=\frac{\text { Valuable Time }}{\text { Loading Time }}
$$

$$
\text { Overall Equipment Effectiveness (OEE) }=\frac{\text { Valuable Time }}{\text { Net Loading Time }}
$$

Whereas the Net Utilization takes into account all the causes of losses and represents the ultimate improvement potential, the OEE takes into account only the losses that are directly ascribable to an equipment. This is because the OEE is a shop-floor metric intended to support the work of the production team (i.e. maintenance operators and production engineers) and focuses exclusively on the effectiveness of a single equipment, rather than that of the factory as a whole (De Ron and Rooda, 2005). Therefore, when computing the OEE one considers the Net Loading Time as the Theoretical Time because this quantity is obtained by subtracting from the Calendar Time both the losses that are external to the manufacturing system and those that are internal but that cannot be directly ascribed to a single equipment, such as blocking and starvation (i.e. equipment independent losses). Note that this approach is correct because the equipment independent losses cannot be eliminated by repairing, improving or redesigning an equipment, but require corrective actions extended to the whole manufacturing system such as modification of the plant layout, machine balancing and buffer re-dimensioning. Considering that, in accordance to Figure 2, equation (5) can be rewritten as:

$$
O E E=\frac{N L T-D T-P L T-Q R T}{N L T}
$$

It is worthy to note that the OEE can also be obtained as the product of three terms, namely: Availability, Performance Rate and Quality Rate. This is shown in equation (7) below:

$$
\begin{aligned}
& O E E=\frac{O p T}{N L T} \times \frac{N O p T}{O p T} \times \frac{V T}{N O p T}=\frac{N L T-D T}{N L T} \times \frac{O p T-P L T}{O p T} \times \frac{N O p T-Q R T}{N O p T}= \\
& =\frac{N L T-D T}{N L T} \times \frac{M I \times C T}{O p T} \times \frac{D F}{M I}=A \times P \times Q(7)
\end{aligned}
$$

where: $C T$ is the ideal Cycle Time, $M I$ is the number of manufactured items, $D F$ is the number of items that do not fit specifications (i.e. defects) and PLT and $Q R T$ are evaluated by means of equations (8) and (9) respectively. 


$$
\begin{aligned}
& \left.P L T=\left(\frac{O p T}{C T}-M I\right) \times C T=O p T-M I \times C T \text { ( } 8\right) \\
& Q R T=(M I-D F) \times C T \text { (9) }
\end{aligned}
$$

\section{Stochastic OEE}

In the standard procedure the effectiveness metrics previously discussed are computed considering all the time losses as deterministic values, although de facto they are random variables. Set-ups and equipment's failures represent good examples to clarify this concept. Indeed it is evident that the duration of set up operations is not fixed, but depends at least: $(i)$ on the sequence of the items that have been manufactured and (ii) on the expertise of the workers that are doing it. Similarly, the duration of down times is a random variable which depends at least: $(i)$ on the severity of the failure and $(i i)$ on the availability of the spare parts needed to repair the damage.

To overcome this weakness, in this section of the paper an innovative procedure that takes into account the variability of the manufacturing process is proposed.

\subsection{Probability distributions of the Time Losses}

The basic idea is to describe each time loss $T_{i}$ by means of a Beta distribution defined on an interval $\left[0, M_{i}\right]$, whose shape parameters $\alpha_{i}$ and $\beta_{i}$ can be evaluated starting from the mean $\bar{x}_{i}$ and the variance $s_{i}^{z}$ of the experimental data, in the following way:

$$
\begin{aligned}
& \alpha_{i}=\frac{\mu_{i}}{M_{i}}\left(\frac{\mu_{i}\left(M_{i} \mu_{i}\right)}{\sigma_{i}^{2}}-1\right) \\
& \beta_{i}=\alpha_{i}\left(\frac{M_{i}-\mu_{i}}{\mu_{i}}\right)
\end{aligned}
$$

As it will be explained later on, the choice of the pdf used to represent the time losses does not significantly affect the final solution (i.e. the computation of the probability density function of the OEE). Nonetheless, the adoption of a Beta distribution is advantageous and is justified by its flexibility and by its ability to handle skewness (Farnum and Stanton 1987). This is an important feature, because a realization (i.e. the observed value) of a time loss $T_{i}$ can never be lower than zero and can rarely be much bigger than its average value. Therefore time losses $T_{i}$ are generally skewed to the right and can be easily modeled using Beta distributions with shape parameters $\alpha>1$ and $\beta \geq$ $\alpha$. In some rare cases, extreme values can be observed too, as for maintenance 
operations. For example if breakdowns do not occur for a certain time the corresponding time loss $T_{i}$ equals zero; conversely if spare parts are not available and/or the maintenance men are over-allocated when a failure occurs, $T_{i}$ can be greater than its average value. As shown in Figure 3, also this condition can be modeled using Beta distributions with shape parameters $\alpha<1$ and $\beta \leq \alpha$.

\section{Take in 'Fig. 3' about here}

The pdf of the Net Loading Time and that of the Valuable Time must be defined as well. To this aim, an approximated approach based on the application of the Central Limit Theorem (CLT) is proposed. Given $n$ independent random variables $X_{i}$, as $n$ increases the CLT assures that the probability distribution of the linear combination $\sum_{i=1}^{n} \alpha_{i} X_{i}$ tends to be normally distributed. In particular, if $\alpha_{i}=1 \mathbf{v i}$, than the obtained Normal distribution $N$ has a mean equal to the sum of the means of the $n$ parent distributions $\left(\mu=\sum_{i=1}^{n}\left[\alpha_{i} \mu_{i}\right) \mathbb{I}\right.$ and variance equal to the sum of the variance of the $n$ parent distributions ( $\sigma^{z}=\sum_{i=1}^{n} \alpha_{i}^{z} \sigma_{i}^{z}$ ). Results of the CLP also apply for non identical and skewed distribution, provided that the following conditions are satisfied (G. D'Agostini 2003):

- existence of finite first and second momentum for all probability distributions;

- $\quad \alpha_{i}^{2} \sigma_{i}^{2} \ll \sigma^{2}, \forall i$

Considering these properties, the adoption of the CLT seems a plausible and straightforward way to obtain the stochastic distributions of the Net Loading Time and that of the Valuable Time, starting from the pdf of all the time losses $T_{i}$. It is easy to see that all the main assumptions concerning the applicability of the CLT are met, indeed:

- $\quad$ although $n$ should tend to infinity, in most practical cases $n \geq 7$ is generally taken as a sufficient threshold value to assure the applicability of the CLT (Law and Kelton, 1997). This condition is fully satisfied, since a sufficient number of time losses (see Figure 3) is included in the model; 
- the existence of a finite first and second momentum directly descends from the consideration that each time loss must be characterized by finite and non null mean and standard deviation;

- the last condition implies that none of the time losses could dominate the fluctuations of the OEE. It seems plausible to assume that the variability of the OEE is not determined by a single time loss (in this case it would be easy to spot and to tackle this loss), but depends, at different levels, on the variability of each one of them.

To apply the CLT, let $G_{l}$ be the gap between the Opening Time and the Net Loading Time and $G_{2}$ be the gap between the Net Loading Time and the Valuable Time (i.e. $G_{1}$ $\left.=N W T+S B T, G_{2}=D T+P L T+Q R T\right)$. Considering that both $G_{1}$ and $G_{2}$ are given by the sum of independent Beta random variables $T_{i}$, the CLT assures that both $G_{1}$ and $G_{2}$ tend to be normally distributed, with mean and variance given by equations (12) and (13), respectively:

$$
\begin{aligned}
& G_{1} \sim N\left(\sum_{i} \mu_{i}, \sum_{i} \sigma_{i}^{2}\right) \\
& G_{2} \sim N\left(\sum_{j} \mu_{j}, \sum_{j} \sigma_{j}^{2}\right)
\end{aligned}
$$

where $i$ and $j$ denote the number of time losses that belong to $G_{l}$ (i.e. lack of demand, stock out, blocking, starving, etc.) and to $G_{2}$ (i.e. failures, set up, start up, defects, etc.), respectively.

Finally, taking the Opening Time as a deterministic value (i.e. the effect of exceptional events is neglected) also the pdf of the Net Loading Time and that of the Valuable Time preserve the normal form. Indeed it results:

$$
\begin{aligned}
& N L T=\left(O T-G_{1}\right) \sim N\left(O T-\sum_{i} \mu_{i}, \sum_{i} \sigma_{i}^{2}\right) \\
& V T=\left(N L T-G_{2}\right) \propto N\left(O T-\sum_{i} \mu_{i}-\sum_{j} \mu_{j}, \sum_{i} \sigma_{i}^{2}+\sum_{j} \sigma_{j}^{2}\right)
\end{aligned}
$$

\subsection{Probability distribution of the Net Utilization}


In accordance with equation (3), the pdf of the Net Utilization can be easily obtained as the ratio of the Opening Time and the Valuable Time. Since the Opening Time is deterministic and the Valuable Time is a normal variable, the Net Utilization preserves the normal form. Therefore the Net Utilization can be expressed as:

$$
N V \sim N\left(\frac{\mu_{x}}{O T} ; \frac{\sigma_{x}^{2}}{O T^{2}}\right)
$$

where $\mu_{x}$ and $\sigma_{x}^{2}$ are the mean and the variance of the Valuable Time.

Being an effectiveness metric, the Net Utilization should be defined on the interval [0; 1], whereas due to the approximation introduced by the use of the CLT, the distribution defined in (16) is boundless. Anyway, in most industrial cases the Opening Time is much greater than $\sigma_{x}^{2}$ and so the Net Utilization has a negligible density for values lower than zero. Conversely a vanishing density in one is not always granted and the distribution must be truncated at the upper bound of the interval. Owing to this, equation (16) becomes:

$$
N U= \begin{cases}\frac{f(x)}{p} & \text { if } x \leq 1 \\ 0 & \text { elsewhere: }\end{cases}
$$

where:

$$
\begin{aligned}
& f(x) \propto N\left(\frac{\mu_{x}}{O T}, \frac{\sigma_{x}^{2}}{O T^{2}}\right)(18) \\
& p=\int_{-\infty}^{1} f(x) d x=\Phi_{1,0}\left(\frac{1-\left(\mu_{x / O T}\right)}{\left(\sigma_{x / O T}\right)}\right)
\end{aligned}
$$

and $\Phi_{1.0}(k)$ is the cumulative distribution of a standard normal distribution $N(0,1)$.

\subsection{Probability distribution of the Overall Equipment Effectiveness}

In a similar way, starting from equation (5), the pdf of the OEE can be obtained as the ratio of the Valuable Time and the Net Loading Time. Unfortunately, the ratio of two normal random variables $X \sim N\left(\mu_{x}, \sigma_{x}^{z}\right)$ and $Y \sim N\left(\mu_{y}, \sigma_{y}^{z}\right)$ does not preserve the normal form. However it is known that the pdf of $W=X / Y$ is given by equation (20):

$f_{W}(w)=\int_{-\infty}^{+\infty}|y| f_{R, Y}(w y, y) d y(20)$

where $f_{X, Y}$ is the joint probability function of $X$ and $Y$. 
If $X$ and $Y$ are independent normal variables with nearly vanishing densities at zero, after some simple calculations one obtains the following closed form expression for the probability density of the ratio $W$ :

$f_{W}(w)=\frac{\sigma_{x}^{2}+\sigma_{y}^{2} \mu_{x} w}{\sqrt{2 \pi}\left(\sigma_{x}^{2}+\sigma_{y}^{2} w^{2}\right)^{\frac{3}{2}}} \exp \left[-\frac{\left(\mu_{x}-\mu_{y} w\right)^{2}}{2\left(\sigma_{x}^{2}+\sigma_{y}^{2} w^{2}\right)}\right]$

It is worth noticing that $f_{W}(w)$ has a Cauchy component and so its mean and standard deviation are undefined (i.e. some elements of $X$ are divided by zero elements of $Y$ ). However, under the hypothesis of $Y$ having a vanishing density at zero (i.e. $\mu_{\mathrm{y}}>3 \sigma_{\mathrm{y}}$ ), $f_{w}(w)$ has a fairly well-defined pseudo mean and pseudo standard deviation, that can be obtained by truncating the usual integrals at some finite limit, where the density falls below some arbitrarily small level.

An example is given in Figure 4, which shows the ratio of two normal distribution $X \sim$ $N(3,0.25)$ and $Y \sim N(4,0.16)$.

Take in 'Fig. 4' about here

Unfortunately, equation (21) cannot be used to compute the pdf of the OEE, because the hypothesis of the independence between $X$ (i.e. the $V T$ ) and $Y$ (i.e. the $N L T$ ) does not hold. Indeed the Valuable Time and the Net Loading Time are dependent (i.e. $V T=$ $\left(N L T-G_{2}\right)$ and their ratio can never be greater that one.

Conversely, even if $\mu_{x} \gg H_{y} f_{W}(w)$ does not necessarily has a vanishing density in one because, due to the hypothesis of independence, some elements of $X$ are divided by some elements of $Y$ that are lower than $X$.

For this reason we suggest to obtain an approximation of the real pdf of the OEE by truncating the function $f_{W}(w)$ in one:

$f_{W}(w)= \begin{cases}\frac{f_{W}(w)}{\int_{0}^{1} f_{W}(w) d w} & \text { if } w \leq \mathbf{1} \\ \mathbf{0} & \text { elsewhere; }\end{cases}$

where $\mu_{x}, \sigma_{x}^{2}, \mu_{y}$ and $\sigma_{y}^{2}$ are the mean and the variance of the Valuable Time and that of the Net Loading Time, respectively.

The integral $I=\int_{-0}^{1} f_{W}(w) d w$ can be easily evaluated as the probability $\mathbf{P}(X \leq Y)$ of $X$ being lower than $Y$. To this aim let $K$ be equal to $(X-Y)$, in this way the probability $\mathbf{P}(X$ 
$\leq Y)$ can be written as $\mathbf{P}(K \leq 0)$. Since $X$ and $Y$ are normal random variable, also $K$ preserves the normal form with mean $\mu_{k}=\mathbb{Z}\left(\mu_{x}-\mu_{y}\right)$ and variance $\sigma_{k}^{2}=\left(\sigma_{x}^{2}+\sigma_{y}^{2}\right)$. Therefore:

$I=\int_{0}^{1} f_{W}(w) d w=\mathbf{P}(K \leq \mathbf{0})=\Phi_{0,1}\left(\frac{0-\mu_{k}}{\sigma_{k}}\right)=\Phi_{0,1}\left(\frac{\mu_{y}-\mu_{x}}{\sqrt{\sigma_{x}^{2}+\sigma_{y}^{2}}}\right)$

Values of $I$ can be obtained from the tables of the cumulative standard normal distribution, or can be read on the graph of Figure 5, where $\mu=\mathbb{Z}\left(\mu_{\mathbb{I}_{x}}-\mu_{y}\right)$ and $\sigma^{2}=\left(\sigma_{x}^{2}+\sigma_{y}^{2}\right)$

\section{Take in 'Fig. 5' about here}

Equation (22) can also be used to evaluate the pdf of the Operation Effectiveness by simply substituting $\mu_{y}$ and $\sigma_{y}^{z}$ with the mean and the variance of the Loading Time instead of that of the Net Loading Time.

\subsection{Validity of the proposed approximation}

As observed in the previous section, as a consequence of the dependence between the Valuable Time (VT) and the Net Loading Time (NLT), equation (22) is just an approximation of the pdf of the OEE. To confirm the validity of this approach and to define its range of applicability, a set of Monte-Carlo simulations were replicated for different levels of the mean and of the variance of the VT and of the NLT. In particular, to adequately represent the values of the OEE and of the time losses that can be found in typical industrial settings, values were generated in accordance to the following scheme:

a) $\mu_{N L T}=100$

b) $\sigma_{\text {NLT }} \in[1,3, \ldots, 27,31]$;

c) $\mu_{V T} \in[35,40, \ldots, 90,95]$ for each value of $\sigma_{N L T}$;

d) $\sigma_{V T} \in\left[1.1 \sigma_{N L T}, 1.3 \sigma_{N L T}, \ldots, 2.9,3.1 \sigma_{N L T}\right]$ for each value of $\sigma_{N L T}$ and of $\mu_{V T}$;

Conditions $a$ and $c$ assure that values of the OEE are generated in the interval [0.3; 0.95]. This interval was considered sufficiently detailed, since an OEE around 90\% represent the excellence, and typical industrial values are around 50-70\%.

Conditions $a$ and $b$ assure that the Coefficient of Variation of the $N L T$ (i.e. $\sigma_{\mathrm{NLT}} / \mu_{\mathrm{NLT}}$ ) ranges in the interval $[0.01 ; 0.31]$. Considering that $\mu_{\mathrm{NLT}}>\mu_{\mathrm{G} 1}$ and that $\sigma_{\mathrm{NLT}} \equiv \sigma_{\mathrm{G} 1}$ a 
$\mathrm{CV}=$ higher that 0.31 is extremely rare in the industrial practice; so also this interval was considered sufficiently detailed.

Finally, condition $d$ assures that, in accordance with equation (15) the standard deviation of the $V T$ is always greater than that of the $N L T$. High values of $\sigma_{\mathrm{VT}}$ (i.e. $\sigma_{\mathrm{VT}} \leq$ $\left.3.1 \sigma_{\mathrm{NLT}}\right)$ were motivated considering that the variability of the time losses comprised in $G_{2}$ is generally higher than that of the time losses comprised in $G_{1}$.

For each examined value of mean and variance, thirty simulations were made, for a total of $30 \times 16 \times 13 \times 16=99840$ replications performed using a program developed using the Matlab Statistical toolbox.

Simulations were carried on in accordance to the following scheme:

- to represent $N L T$ and $G_{2}$ two vectors $X(i)$ and $Y(i)$ of 100 normal random variables (a sample sufficiently wide to correctly represent the OEE population, without compromising the speed of each simulation run) have been created under the constraint that $X(i) \geq Y(i)$;

- starting from these vectors the $V T$ and the OEE have been derived as $Z(i)=[X(i)$ $Y(i)]$ and $\mathrm{W}(i)=[Z(i) / X(i)]$, respectively;

- to test the null hypothesis that $f_{\text {何 }}(\bar{w})$ is the pdf of the sample $W(i)$ a KolgomorovSmirnov test has been carried out.

An example of the obtained results is given in Figure 6, which shows the average Pvalue (i.e. the probability of observing the given sample under the assumption that the null hypothesis is true) obtained for different levels of the mean of the VT.

Take in 'Fig. 6' about here

The comparison of the experimental histogram with the theoretical pdf and that of the experimental with the theoretical cumulative distribution function are shown in Figure 7 and 8 , respectively.

Take in 'Fig. 7' about here

Take in 'Fig. 8' about here 
As can be observed in Figure 6, the fitting improves when the OEE is lower than $90 \%$ (i.e. $\mu_{\mathrm{VT}}<90$ ), whereas after this point the P-values rapidly decreases and the Kolgomorov-Smirnov test tends to reject the null hypothesis. Furthermore, the approximation works better when the difference between the standard deviation of the $N L T$ and that of the $V T$ increases (i.e. the standard deviation of $G_{2}$ is high). Note that this behavior can be explained remembering that $V T=\left(N L T-G_{2}\right)$. As a consequence, the greater are the mean and the standard deviation of $G_{2}$ the more $V T$ differs from $N L T$ and the hypothesis of independence (of these variables) is satisfactory.

Also note that both these conditions do not represent a serious limit to the applicability of the proposed approach. Indeed, especially for the manufacturing industry, values of the OEE greater than $85-90 \%$ represent the excellence, whereas the proposed approach is intended to facilitate the understanding and the reduction of the main causes of wastes in industries where Lean Manufacturing has not been introduced yet, and the OEE is in the range $50-70 \%$. Additionally, before the introduction of Lean Manufacturing, the hypothesis of a high variability of $G_{2}$ is generally verified, since for most of the time losses $T_{i}$ (such as failure, set up, minor stoppages, etc.) very high and very low values can be observed with a certain frequency.

Repeating the Monte Carlo simulation for different ratios of the mean and the variance of $G_{2}$, the range of validity of the proposed approximation has been numerically obtained. The range of validity is given in Figure 9, which graphically shows the maximum value of the ratio between the mean of the Valuable Time and that of the Net Loading Time (i.e. the maximum value of the OEE) for which the average of the Pvalue is greater than 0.3 and the approximation can be effectively used.

\section{Take in 'Fig. 9' about here}

\section{Evaluation of potential corrective actions}

The use of Beta distributions as a practical way to describe the time losses $T_{i}$ is particularly helpful to estimate the effects of potential corrective actions on the OEE. For example, if down time and set up are the major causes of losses, a possibility could be that of adopting a preventive maintenance strategy to reduce the frequency of failures or to use SMED techniques (i.e. Single Minute Exchange of Dies) to reduce set up 
times. To decide which corrective action should be deployed first, one should be able to evaluate their potential effects in terms of both efficiency and efficacy. As discussed in the introduction, when dealing with corrective actions, the efficiency and the efficacy can be assimilate to the precision and to the accuracy of the obtained results, respectively. Therefore, taking the percentage change in the mean and in the standard deviation of the OEE as estimation of the efficiency and of the efficacy of the corrective action, this can be done by means of the following metrics:

$$
\begin{aligned}
& \text { Efficiency of the jth corrective action }=\eta_{\mathrm{j}}=\frac{\hat{\mu}_{O E E j}-\mu_{O E E}}{\mu_{O E E}}(24) \\
& \text { Efficacy of the jth corrective action }=\phi_{j}=\frac{\hat{\sigma}_{O E E j}-\sigma_{O E E}}{\sigma_{O E E}}
\end{aligned}
$$

where $\hat{A}_{O E E j}$ and $\hat{\sigma}_{O E E j}$ are the mean and the standard deviation of the OEE obtained through the deployment of the $j$-th corrective action.

To estimate $\hat{\mu}_{O E E j}$ and $\hat{\sigma}_{O E E j}$ before the deployment of the $j$-th corrective action a heuristic procedure valid for Beta random variables can be used (Law and Kelton, 1991). To this aim, for each $j$-th corrective action production engineers are asked to give a pessimistic and a reasonable evaluation of the obtainable reduction of the corresponding time losses $T_{i}$. These values are then used in equations (26-27) to estimate the new expected mean $\mu_{i j}$ and the expected variance $\sigma_{i j}^{z}$ of $T_{i}$ :

$$
\begin{aligned}
& \mu_{i j}=\frac{a_{i j}+4 m_{i j}+b_{i j}}{6} \cong \frac{4 m_{i j}+b_{i j}}{6}(26) \\
& \sigma_{i j}^{2}=\frac{\left(b_{i j}-a_{i j}\right)^{2}}{36} \cong \frac{b_{i j}^{2}}{36}
\end{aligned}
$$

Where $a_{i j}, m_{i j}$ and $b_{i j}$ are the optimistic, the expected and the pessimistic value of $T_{\mathrm{i}}$ when the $j$-th corrective action is developed. In addition the hypothesis is made that the optimistic value of $T_{i} \cong 0$.

Finally, by means of equations (12-22) the new pdf of the $\mathrm{OEE}_{j}$, its mean $\hat{H}_{O E E j}$ and its standard deviation $\hat{\sigma}_{O E E j}$ can be easily obtained for each $j$-th corrective action.

Instead of using equations (24-25), the choice (among a set of potential corrective actions) can also be made by directly comparing the pdf of the OEE obtained for each one of the corrective actions. Without loss of generality, let's take two alternative distributions of the OEE with $\hat{\mu}_{O E E 1}>\hat{\mu}_{O E E z}$. Unless $\hat{\sigma}_{O E E 1}<\hat{\sigma}_{O E E z}$ the choice 
between $\mathrm{OEE}_{1}$ and $\mathrm{OEE}_{2}$ is not obvious because the two cumulative function $\mathrm{F}_{1}(w)$ and $\mathrm{F}_{2}(w)$ have an interception point $w^{*}$ and so:

$\mathbf{P}\left(O E E_{1} \leq w\right)>\mathbf{P}\left(O E E_{2} \leq w\right) \quad \forall w \leq w^{*}$

$\mathbf{P}\left(O E E_{1} \leq w\right)<\mathbf{P}\left(O E E_{2} \leq w\right) \quad \forall w>w^{*}$

In this case, the easiest way to rank the solutions is to compare the intersection value $w^{*}$ with a critical value of the $\mathrm{OEE}^{*}$ (i.e. the minimum acceptable value of the OEE) or, to evaluate the probability $P_{j}$ of each $j$-th solution to exceed the critical OEE*

$$
\mathrm{P}_{\mathrm{i}}\left(O E E_{j} \leq O E E^{*}\right)=\alpha_{j}
$$

The $j$-th solution that gives the lowest value of $\alpha$ is chosen as the best one.

Alternatively, if one does not want to subjectively define the critical value, the rank can be obtained by computing the probability of $\mathrm{OEE}_{1}$ being lower that $\mathrm{OEE}_{2}$ when both $\mathrm{OEE}_{1}$ and $\mathrm{OEE}_{2}$ are lower than $\mu_{O E E 1}$ (Braglia et al., 2009).

In this case one gets the following expression:

$$
O E E_{1}<O E E_{2} \text { if } P_{12}=P\left(O E E_{1}<O E E_{2} \mid O E E_{1}, O E E_{2} \geq \mu_{O E E 1}\right)>0.5
$$

where:

$$
\begin{aligned}
& P_{12}=\frac{P\left(O E E_{1}<O E E_{2}\right) \cap\left[P\left(O E E_{1}<\mu_{O E E 1}\right) \cap P\left(O E E_{2}<\mu_{O E E 1}\right)\right]}{\left[P\left(O E E_{1}<\mu_{O E E 1}\right) \cap P\left(O E E_{2}<\mu_{O E E 1}\right)\right]}= \\
& =\frac{\int_{\mu_{Q E E 1}}^{1} f_{W_{2}}\left(w_{2}\right)\left[\int_{0}^{W_{2}} f_{w_{1}}\left(w_{1}\right) d w_{1}\right] d w_{2}}{F_{1}\left(\mu_{O E E 1}\right) F_{2}\left(\mu_{O E E 1}\right)}(30)
\end{aligned}
$$

It is worth noticing that the rank obtained by means of equation (28) is less cautionary than that obtained with equation (30). Indeed, in the latter case the probability of the OEE being greater than $\mu_{O E E 1}$ is neglected and only the left side variability of the OEE is taken into account.

\section{An industrial application}

The proposed approach has been applied to evaluate the effectiveness of an equipment for the production of waterproofing coatings, which are used in dumps to avoid the leaching of polluted sullages into the ground. 
The coatings, constituted of a layer of inert matter (i.e. bentonite) interposed between two waterproof canvases, are realized in the following way: $(i)$ the upper and the lower canvas are winded up on two reels that can turn on an idle axels, (ii) a series of motorized rollers are used to drag the upper and the lower canvas inside the machine and to kept them separated, (iii) a mixture of glue, hardening foam and bentonite is placed on the lower canvas, (iv) the upper and the lower canvases are joined together to form the layer, $(v)$ the layer is heated in a kiln, calandered by a series of pressurized rolls and finally cut into pieces of the required length.

The mean and the standard deviation of the weekly time losses (expressed in minutes) are listed in Table 1. Data have been gathered every week (i.e. every five working days) for a period of three months. As can be seen, change over represents one of the main causes of waste: this is because the replacement of the reels of the canvas is a time consuming operation (that requires sixteen minutes on average), which is repeated four times every day.

Take in 'Table 1' about here

In particular, as soon as a reel is coming to an end, the equipment is stopped, a new one is inserted in the idle axels and the edge of the old canvas is joined to the edge of the new one. The fastening is made by overlapping the edges of the two canvases and by sticking them with a tape along the red line shown in Figure 10.

Take in 'Fig. 10' about here

Once the fastening is completed, the equipment is restarted at very low speed until the union of the edges passes through all the motorized rolls and reaches the end of the equipment. At this point the old and the new canvas are detached and the manufacturing activities can restart at the nominal pace.

All the phases of the changeover can be made by a single worker, with the exception of the union of the canvases, which requires the collaboration of two workers. This is the cause of the high variability of change over times, because the first worker must frequently wait for the arrival of the second one, who is not always available. To overcome this problem, a simple solution has been hypothesized: by welding a metal 
bearing on the front size of the equipment and using it as a fixed support for the tape, a single worker would be able to unroll the tape and to join the canvases by his own, as clearly shown in Figure 11 and 12.

Take in 'Fig. 11' about here

Take in 'Fig. 12' about here

With the introduction of this solution, the expected and the pessimistic duration of a changeover have been estimated in 22 and in 24 minutes, respectively. Thus, considering that changeover is repeated four times per days, by means of equations (2627) one obtains an estimation of the mean and of the standard deviation of 373 and 80 minutes per week, respectively. Note that the average time that is lost to make changeover has slightly increased, but its variance has significantly decreased. This is logical because, as a consequence of the corrective action, the whole change over operation is now carried on by a single worker instead of two.

To evaluate the goodness of this corrective action equations (12-23) have been used. The obtained results are graphically showed in Figure 13, which displays the Net Utilization, the Operating Effectiveness and the Overall Equipment Effectiveness before and after the introduction of the corrective action (i.e. $\mathrm{OEE}_{1}$ and $\mathrm{OEE}_{2}$ ).

Take in 'Fig. 13' about here

In this case $\mu_{O E E 1}>\hat{\mu}_{O E E 2}$ and $\sigma_{O E E 1}>\hat{\sigma}_{O E E 2}$ and the choice between the introduction of the corrective action and the preservation of the status quo is not obvious, because the two cumulative function $\mathrm{F}_{1}(w)$ and $\mathrm{F}_{2}(w)$ intercept in $w^{*}=0.61$, as clearly shown in Figure 14.

Take in 'Fig. 14' about here

In accordance with equation (28), if one accepts a critical value $\mathrm{OEE}^{*}<0.61$, deploying the corrective action is the best option, and vice versa. 
In the present case, the definition of the critical value was straightforward: indeed, to implement a continuous process pulled by the customer, the operating cycle time must be lower or equal than the Takt Time, which is the maximum time per unit allowed to produce a product in order to meet the customer's demand. Therefore, since the operating cycle time is defined as the ratio of the nominal cycle time and the OEE, the following condition must be satisfied:

\section{$\frac{\text { Nominal Cycle Time }}{\text { OEE" }}=$ Takt Time}

Due to an expected demand of 40 waterproofing coatings per day (i.e. a Takt Time of 12 minutes) and to a nominal cycle time of 7 minutes, a critical values of $58.3 \%$ was found and, consequently, it was decided to implement the corrective action.

As demonstrated in Figure 14, although this solution implies a small increase of the average cycle time (from 11 to 11.05 minutes), this (negative) effect is abundantly compensated by the obtained reduction of variability that permits to increase the probability to respect the Takt Time. It is interesting to note that an improvement that increases the operating cycle time and reduces its variability is quite common when there is a sufficient gap between the operating cycle time and the Takt Time (Rother and Harris, 2001). This is because, if the operating cycle time is shorter than the Takt Time a further reduction is not always desirable, for it could be a cause of overproduction. Conversely, a reduction of variability is always desirable, for it permits to stabilize the manufacturing process and to simplify production planning and control.

In a similar way, the opportunity to deploy the corrective action is also confirmed by equation (30), which gives a value $P_{12}$ equal to 0.537 .

$$
\begin{gathered}
P_{12}=\frac{\int_{0.685}^{1} f_{w_{2}}\left(w_{2}\right)\left[\int_{0}^{w_{2}} f_{w_{1}}\left(w_{1}\right) d w_{1}\right] d w_{2}}{F_{1}(0.635) F_{2}(0.635)}= \\
=\frac{\int_{0695}^{1} f_{W_{2}}\left(w_{3}\right)\left[\int_{0}^{w_{2}} f_{w_{2}}\left(w_{1}\right) d w_{1}\right] d w_{2}}{0.503 \times 0.512}=0.537
\end{gathered}
$$

Since $P_{12}>0.5$, accordingly to equation (29) $\mathrm{OEE}_{1} \leqslant \mathrm{OEE}_{2}$ and the deployment of the corrective action is confirmed as the best alternative. As previously observed this approach is more cautionary and privileges the second solution, because it reduces the variance of the OEE, assuring a low probability to get an extremely low OEE. 
Finally, it is worthy to note that the average value of the $\mathrm{OEE}_{1}$ and of the $\mathrm{OEE}_{2}$ (i.e. the value of the OEE before and after the introduction of the corrective action) could have been obtained also through a straight application of the deterministic approach. Unfortunately, since the deterministic approach is not capable to capture the reduction of variability obtainable through the deployment of the corrective action, the corrective action would have not been implemented, because $\mathrm{OEE}_{1}=63.5 \%$ is greater than $\mathrm{OEE}_{2}$ $=63.3 \%$.

This clearly demonstrates the superiority of the stochastic approach over the deterministic one, since the latter would lead to an incorrect decision (i.e. refusal of an useful corrective action).

\section{Conclusions}

In this paper the OEE has been introduced as a practical way to analyze and to reduce the main causes of waste and to support Lean Manufacturing and Total Productive Maintenance. Furthermore, the main pitfalls of the OEE have been briefly pinpointed and discussed; in particular it was shown that being a deterministic value, the OEE is not capable to point out the variability of a manufacturing process. This is a major limitation because variability is one of the main causes of waste and must be reduced before Lean Manufacturing can be set into place. To this aim, an approximated approach based on the CLT has been proposed to derive the pdf of the OEE starting from the pdf of the main determinant of waste. In this way one can evaluate the OEE, taking into account both its mean and the standard deviation, and can compare in statistical terms the impact of alternative corrective actions.

Since the proposed approach introduces some approximations, a set of Monte Carlo simulations have been performed to confirm its validity and to define its range of applicability. In particular, it was proved that the method is valid for values of the OEE lower than $90 \%$ and when the variability of the equipment internal losses is high. It has also been shown that both conditions apply in most of the practical cases and the validity and the applicability of the approach has been finally confirmed by an industrial application of relevance. The industrial application also demonstrates that, especially if there is a sufficient gap between the operating Cycle Time and the Takt Time, reducing the OEE variability is generally preferable than reducing its average value. This 
confirms the superiority of the stochastic approach over the deterministic one, since the variability of the OEE can be assessed only by means of the stochastic approach. 


\section{References}

Braglia, M., Carmignani, G. and Zammori, F., 2006. A new value stream mapping approach for complex production systems. International Journal of Production Research, 44 (18), 3929 - 3952.

Braglia, M., Frosolini, M. and Zammori, F., 2008. Overall equipment effectiveness of a manufacturing line (OEEL), an integrated approach to assess systems performance. Journal of Manufacturing Technology Management, 20 (1), 8-29.

Braglia, M., Frosolini, M. and Zammori, F., 2009. Uncertainty in value stream mapping analysis. International Journal of Logistic Research and Applications, 12 (6), 435 453.

Bulent, D., Tugwell, P. and Greatbanks, R., 2000. Overall equipment effectiveness as a measure of operational improvement- A practical analysis. International Journal of Operations and Production Management, 20 (12), 1488-1502.

D’Agostini, G., 2003, Bayesan reasoning in data analysis, a critical introduction, World Scientific Publishing.

Dhandapani, V., Potter, A. and Naim, M., 2004. Applying Lean Thinking, a case study of an Indian steel plant. International Journal of Logistic Research and Applications, 7 (3), 239-250.

De Ron, A.J. and Rooda, J.E., 2005. Equipment Effectiveness: OEE Revisited", IEEE transaction on semiconductor manufacturing. 18 (1), 190-196.

De Ron, A.J. and Rooda, J.E., 2006. OEE and equipment effectiveness: an evaluation. International Journal of Production Research, 44 (23), 4987-5003.

Emiliani, M., 2000. Cracking the code of business. Management Decision, 38, 60-79.

Farnum, N.R. and Stanton L., 1987. Some Results Concerning the Estimation of Beta Distribution Parameters in PERT. The Journal of the Operational Research Society, 38 (3), 287-290.

George, M.L., 2002. Lean Six Sigma: Combining Six Sigma Quality with Lean Production, McGraw-Hill, USA

Gouvêa da Costa, S.E. and Pinheiro da Lima, E., 2002. Uses and Misuses of the Overall Equipment Effectiveness for production management. Proceedings of IEMC 2002 IEEE International, Cambridge, UK, 2, 816-820. 
Hines, P. and Rich, N., 1997. The seven value stream mapping tools. International Journal of Operations \& Production Management, 17 (1), 46-64.

Hines, P., Holweg, M. and Rich, N., 2004. Learning to Evolve, a review of contemporary lean thinking. International Journal of Operations \& Production Management, 24 (10), 994-1011.

Hopp, W.J. and Spearman, M.L., 2000. Factory Physics, McGraw-Hill, New York, NY.

Jeong, K.Y. and Phillips, D.T., 2001. Operational efficiency and effectiveness measurement. International Journal of Operations \& Production Management, 21 (11), 1404-1416.

Jonsson, P. and Lesshammar, M., 1999. Evaluation and Improvement of manufacturing performance measurement system the role of the OEE. International Journal of Operations and Production Management, 19 (1), 55 - 78.

Law, A.M. and Kelton, W.D., 1991. Simulation Modeling and Analysis, McGraw-Hill, New York, NY.

Ljungberg, O., 1998. Measurement of overall equipment effectiveness as a basis for TPM activities. International Journal of Operations and Production Management, 18 (5), $495-507$.

McDonald, T., Van Aken M.E. and Rentes A.F., 2002. Utilizing Simulation to Enhance Value Stream Mapping: A Manufacturing Case Application. International Journal of Logistics Research and Applications, 5 (2), pp. 213 - 232.

Muchiri, P. and Pintelon, L., 2008. Performance measurement using overall equipment effectiveness (OEE): literature review and practical application discussion. International Journal of Production Research, 46 (13), 3517 - 3535.

Nakajima, S., 1988. An Introduction to TPM, Productivity Press, Portland, OR.

Ohno, T., 1988. The Toyota Productive System: Beyond Large-Scale Production. Productivity Press, Portland, OR.

Rother, M. and Harris, R., 2001. Creating Continuous Flow: An Action Guide for Managers, Engineers and Production Associates. Lean Enterprise Institute, Cambridge, MA.

SEMI E10-96, 1996. Standard for Definition and Measurement of Equipment Productivity. 
Shingo, S., 1981. Study of the Toyota Production System. Japan Management Association, Tokio, Japan. 


\section{FIGURE CAPTIONS}

Figure 1. Variability of the OEE

Figure 2. The OEE Losses Classification Structure

Figure 3. An example of Beta random variables

Figure 4. An example of the ratio of two normal variables

Figure 5. Some values of the normalization factor I

Figure 6. Typical results of the Monte Carlo simulations

Figure 7. Comparison of the experimental histogram with the theoretical pdf

Figure 8. Comparison of the experimental with the theoretical cdf

Figure 9. The range of validity of the proposed approximation

Figure 10. The junctions of the canvases

Figure 11. The fixed support for the tape

Figure 12. The implementation of the corrective action

Figure 13. The effectiveness metrics of the equipment

Figure 14. Comparison of the OEE before and after the corrective action 


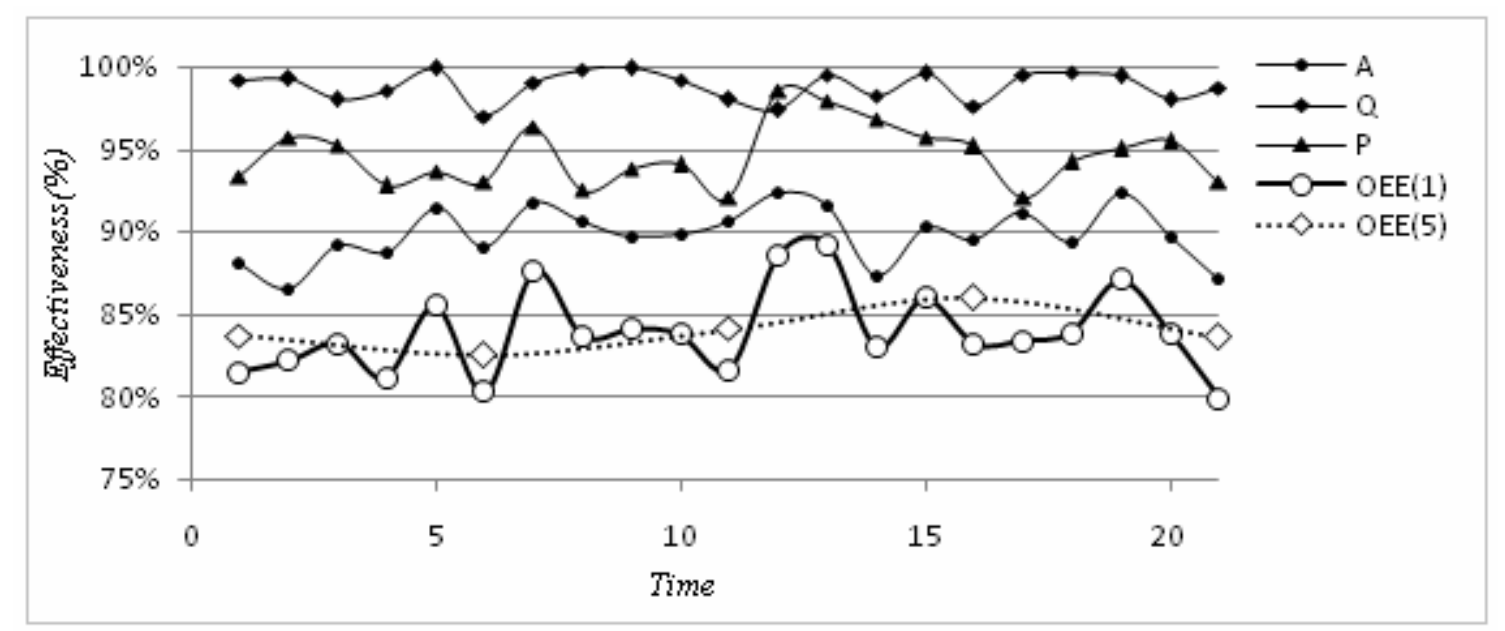

Figure 1. Variability of the OEE 


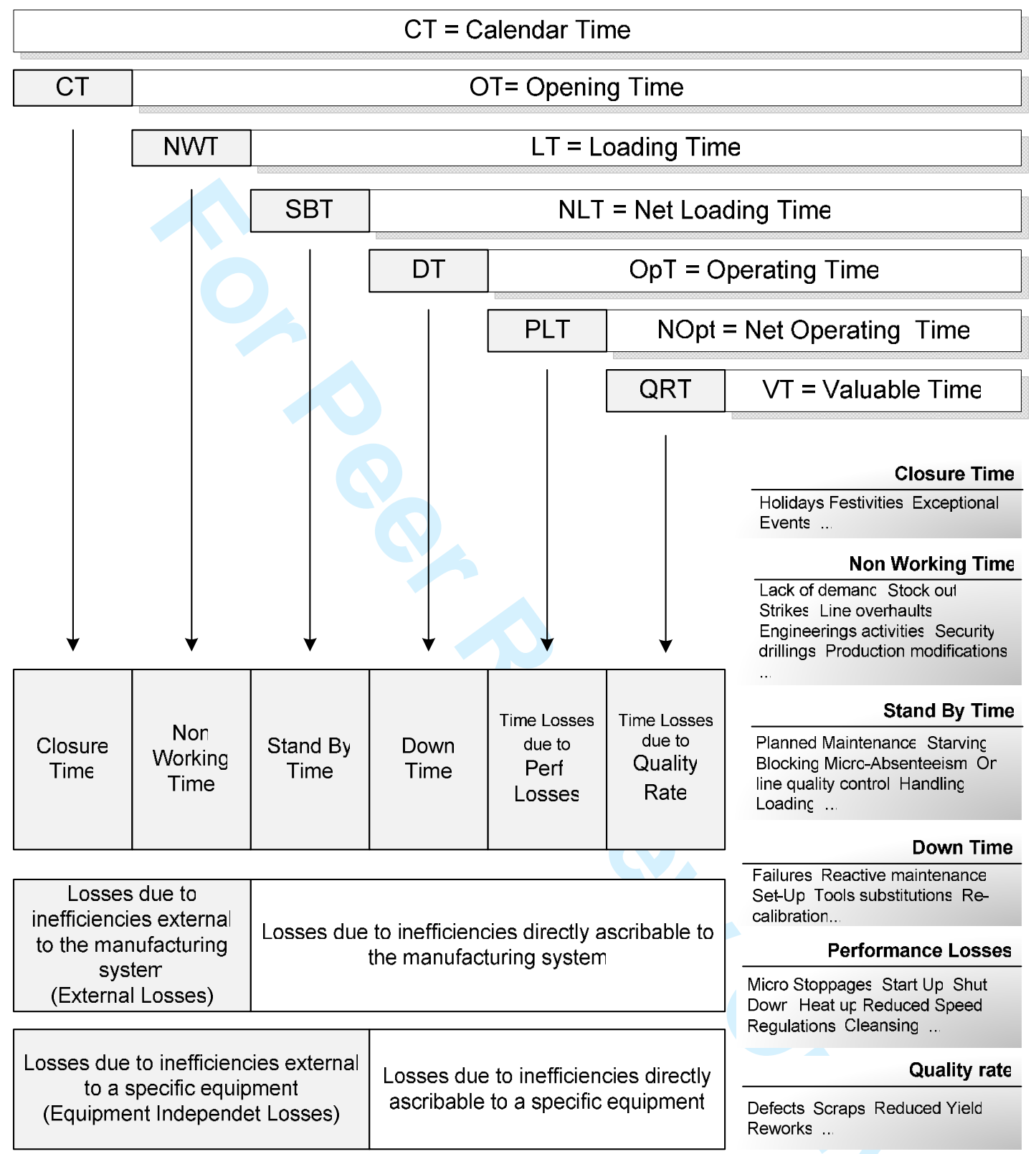

Figure 2. The OEE Losses Classification Structure 


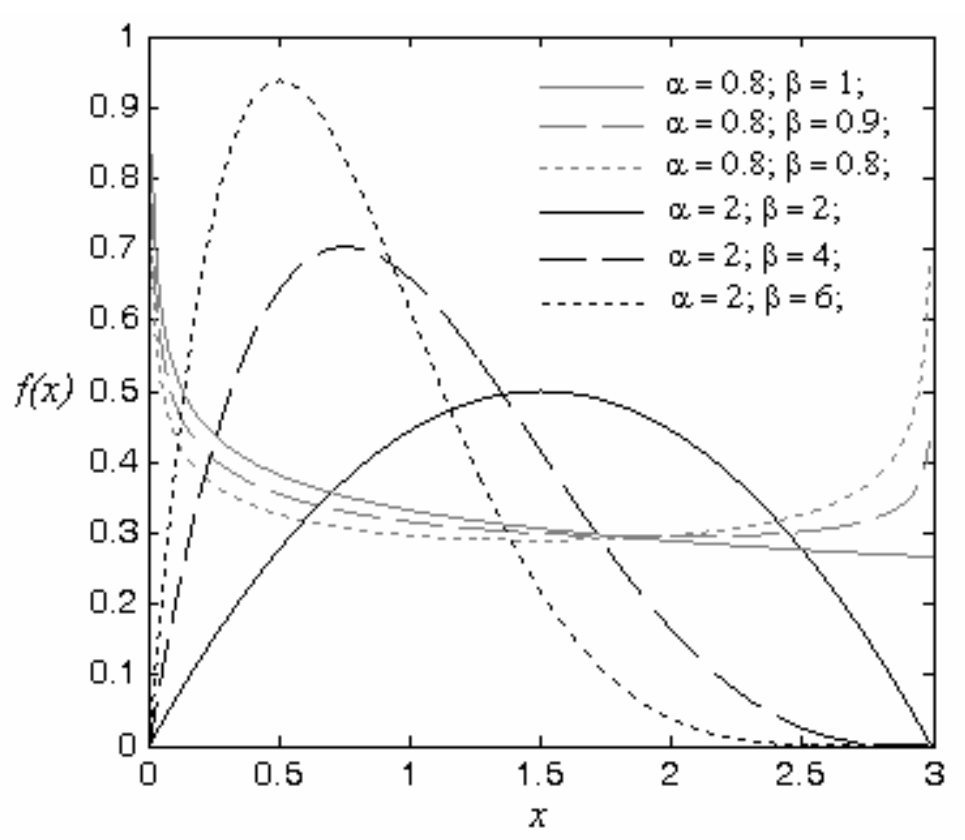

Figure 3. An example of Beta random variables 


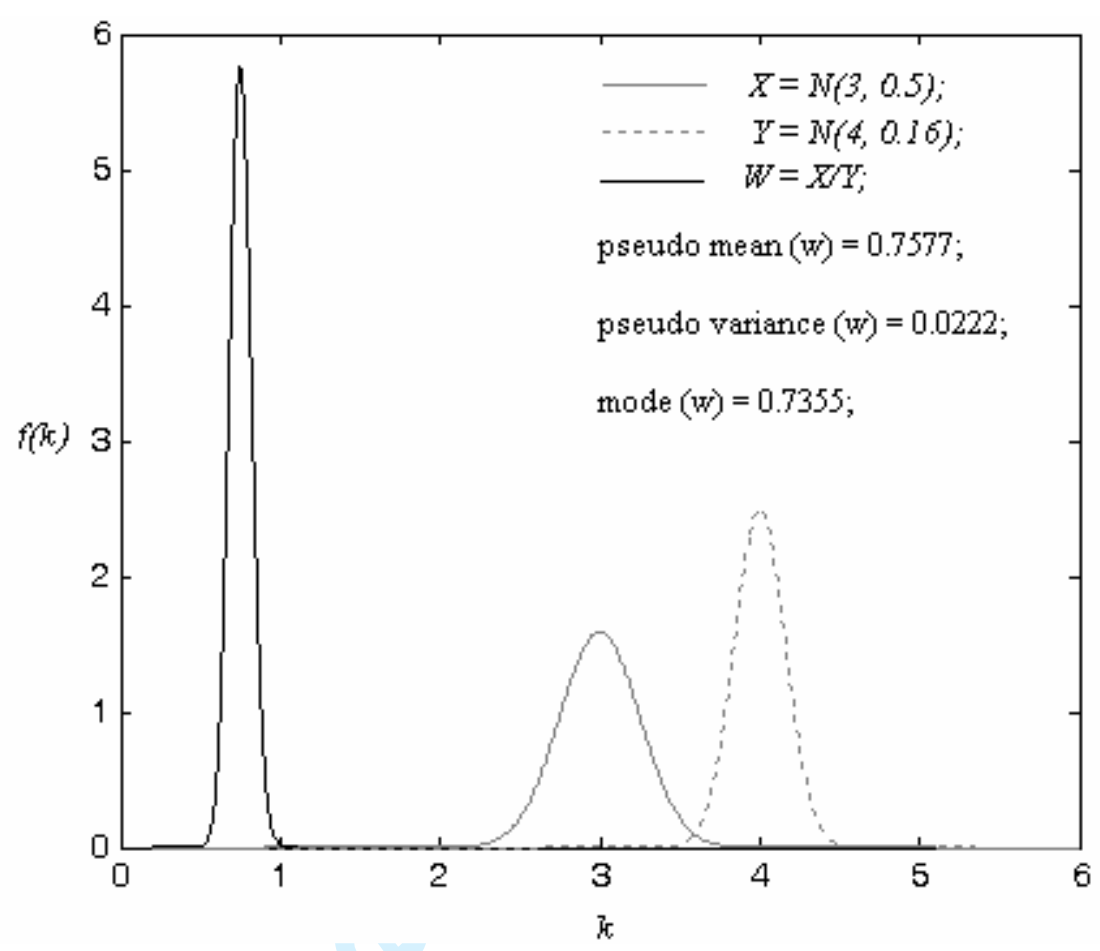

Figure 4. An example of the ratio of two normal variables 


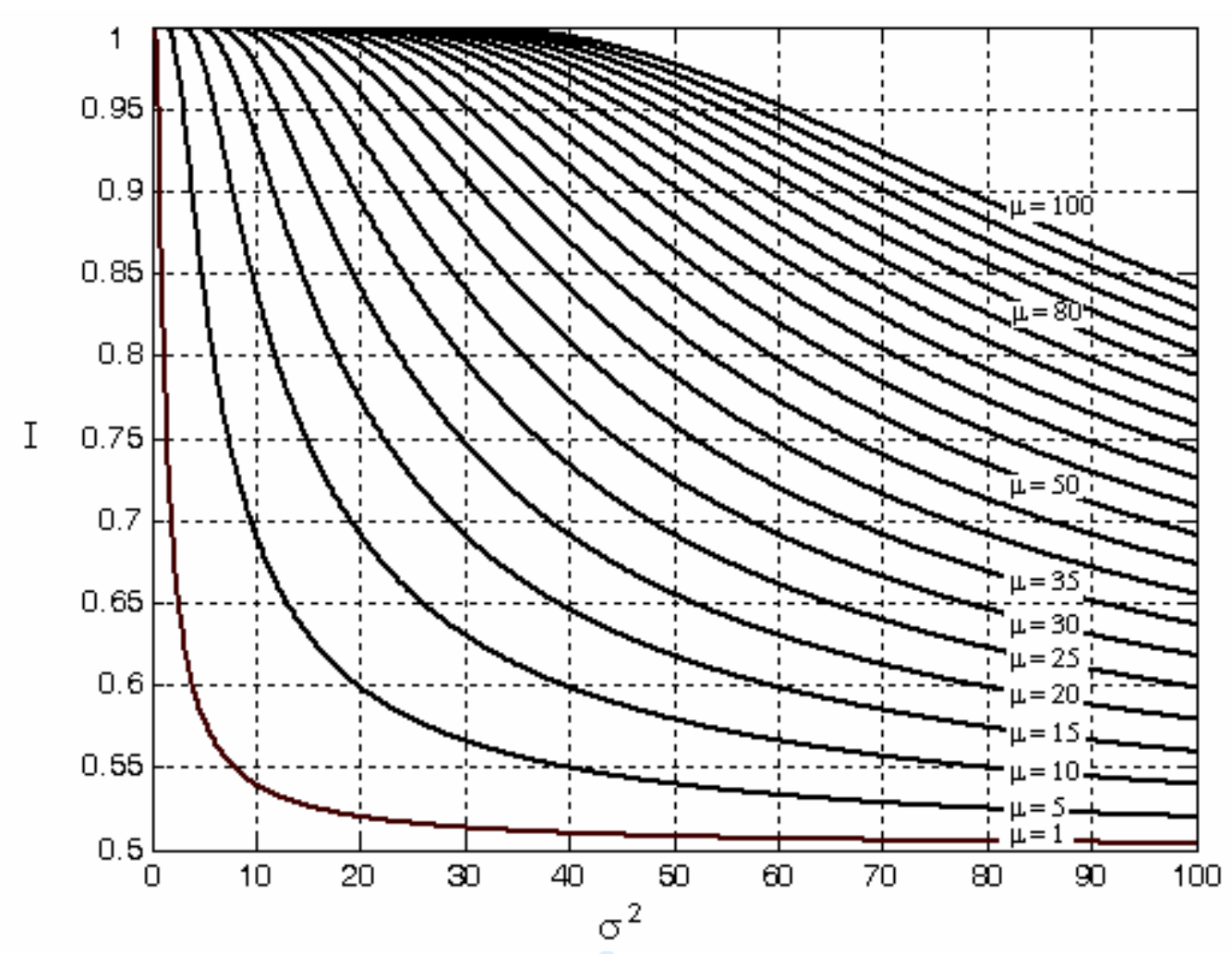

Figure 5. Some values of the normalization factor I 

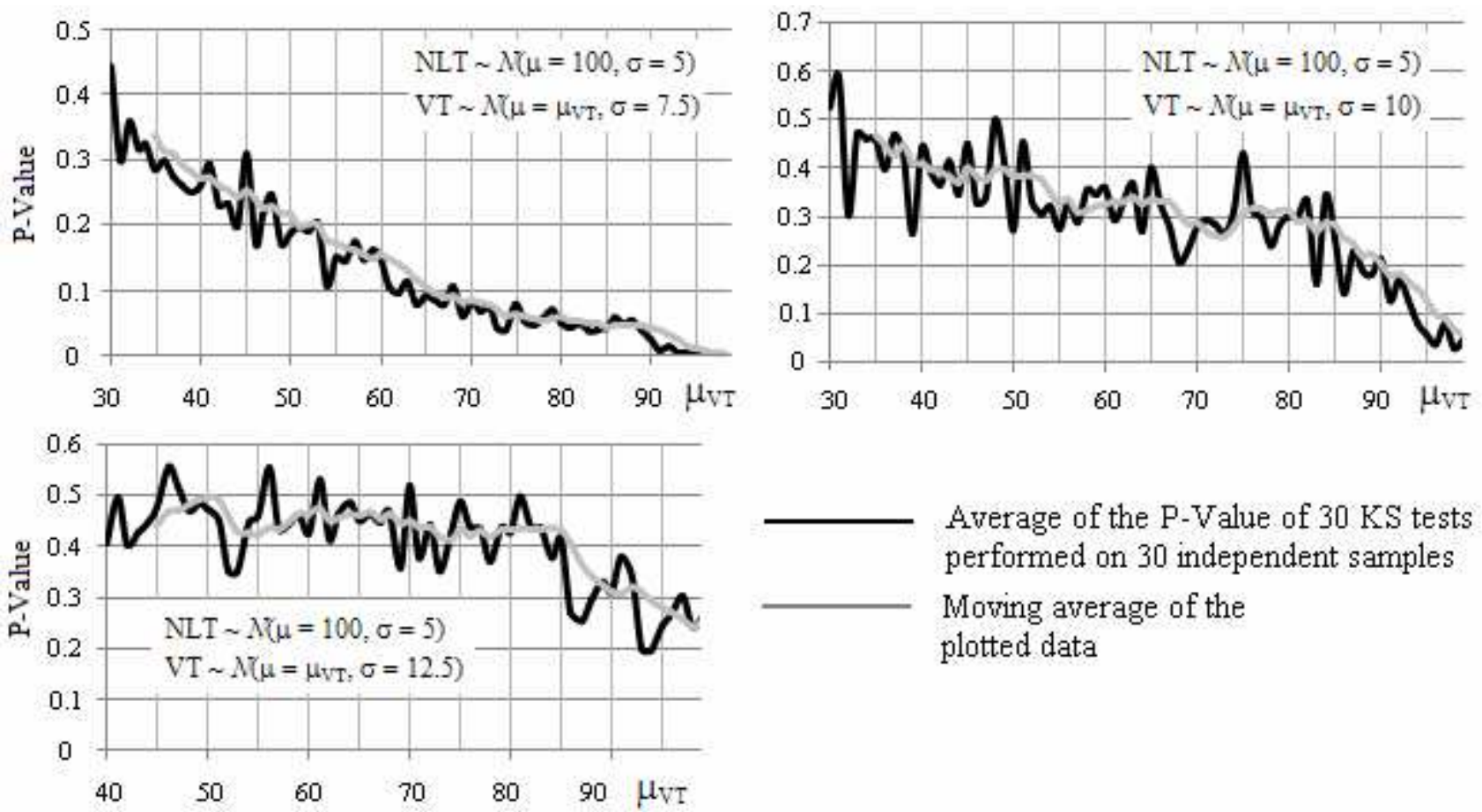

Average of the P-Value of $30 \mathrm{KS}$ tests performed on 30 independent samples

Mowing average of the plotted data

Figure 6. Typical results of the Monte Carlo simulations 


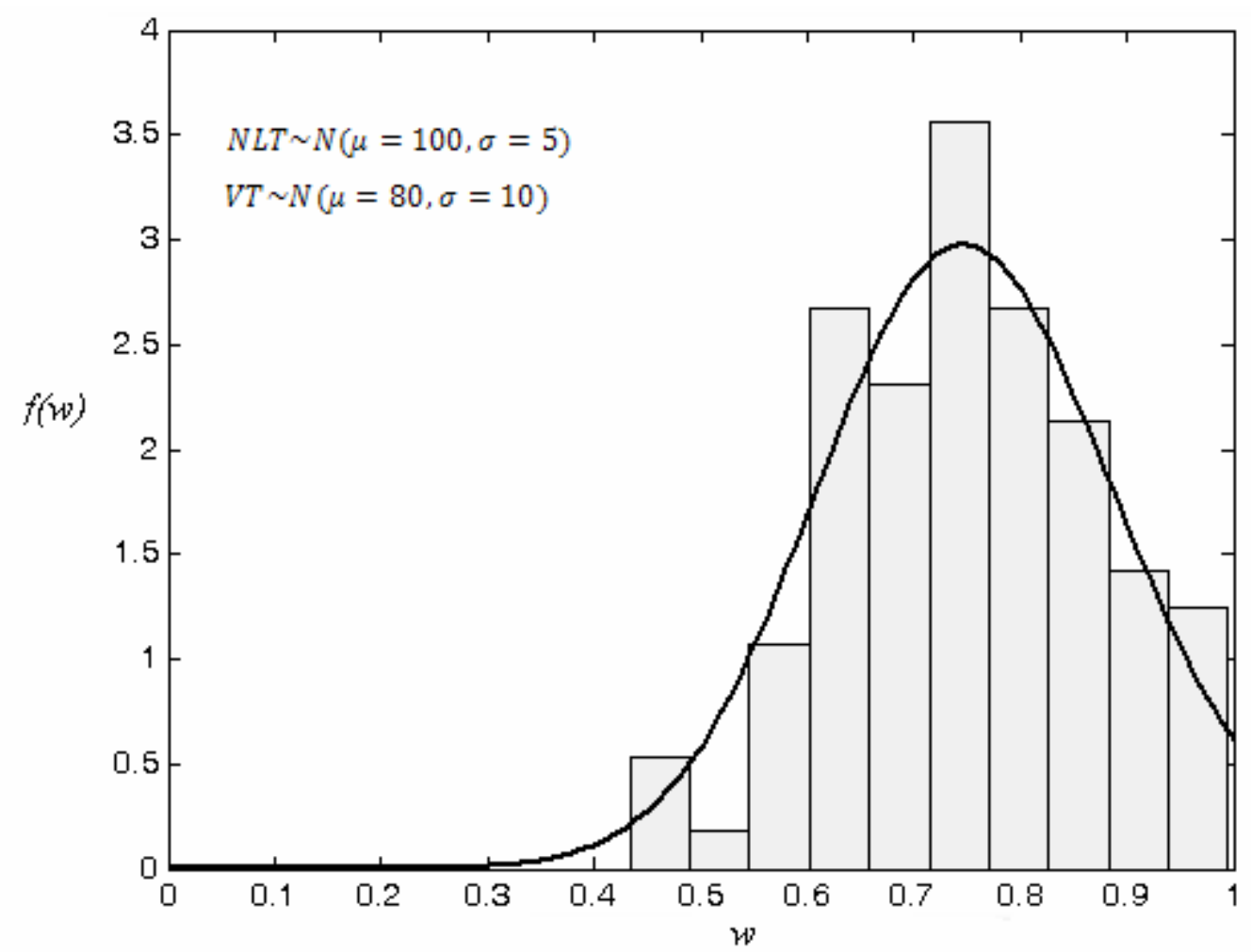

Figure7. Comparison of the experimental histogram with the theoretical pdf 


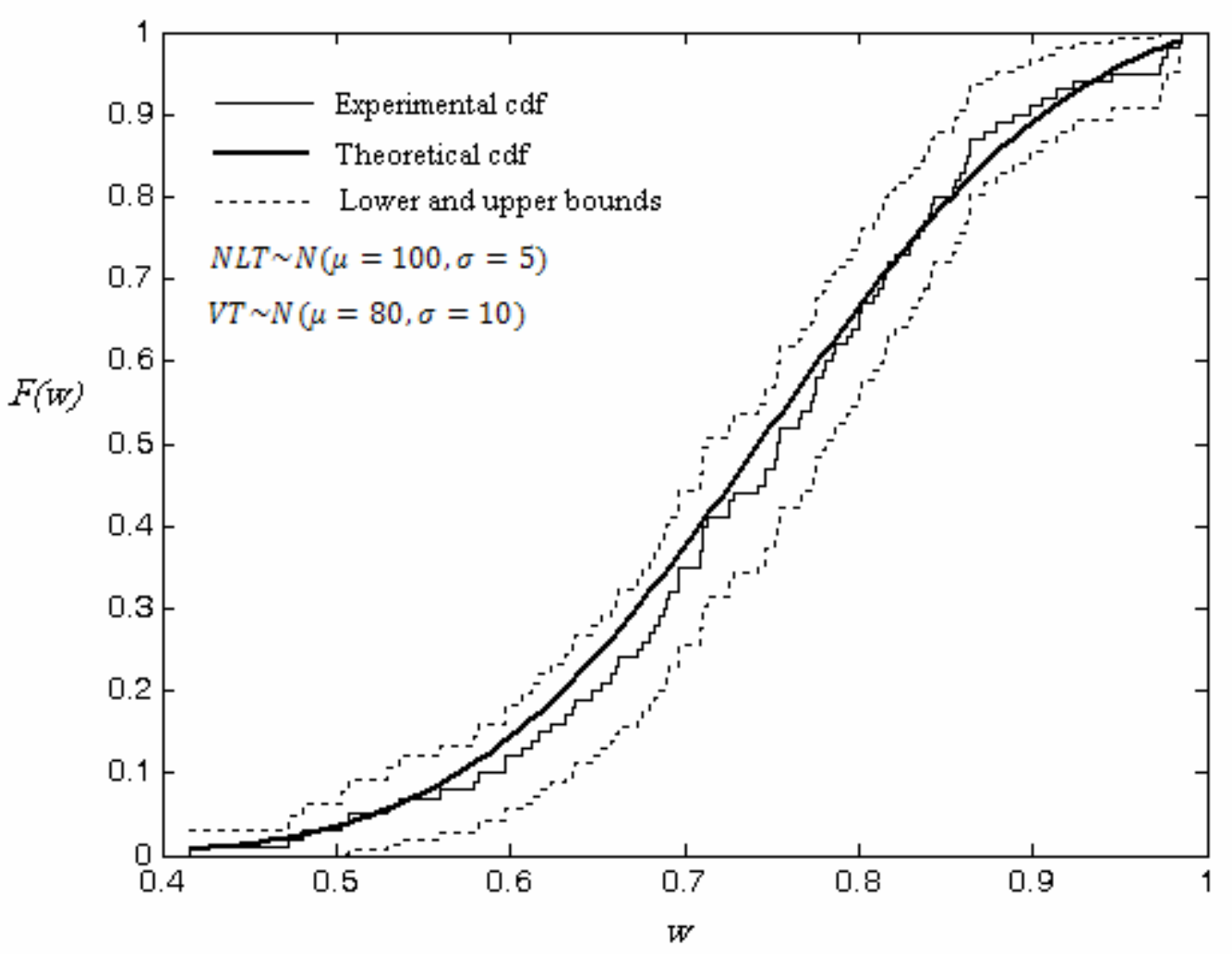

Figure 8. Comparison of the experimental with the theoretical cdf 


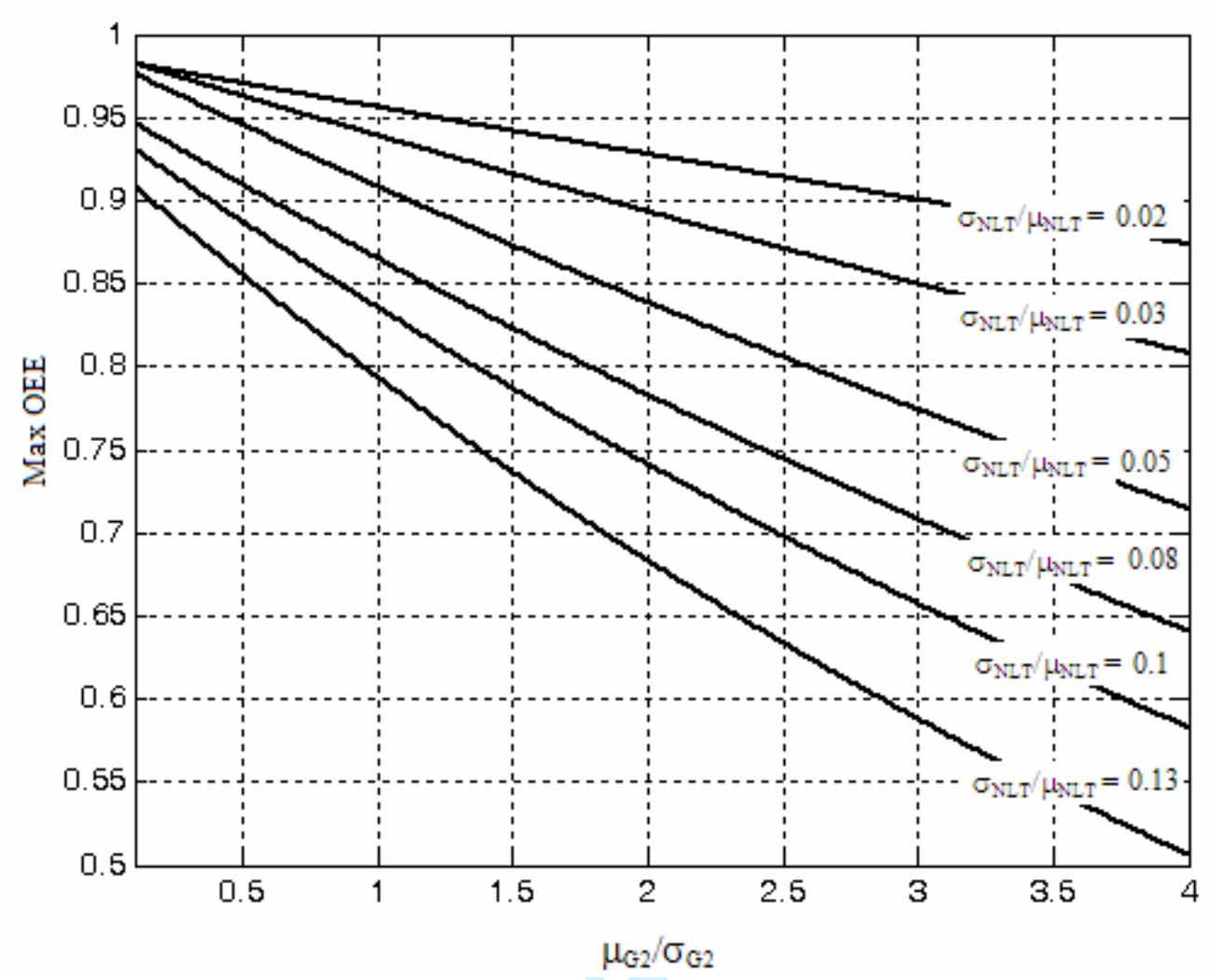

Figure 9. The range of validity of the proposed approximation 


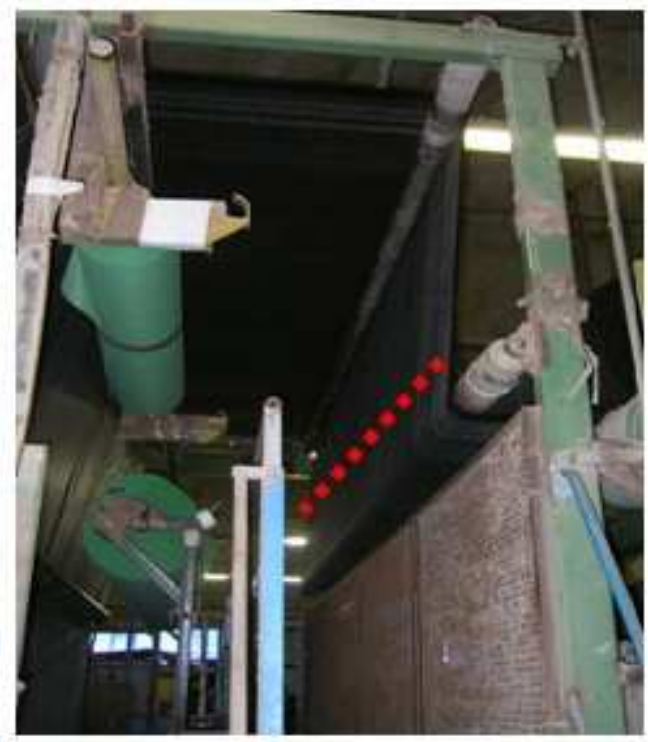

Figure 10. The junctions of the canvases 


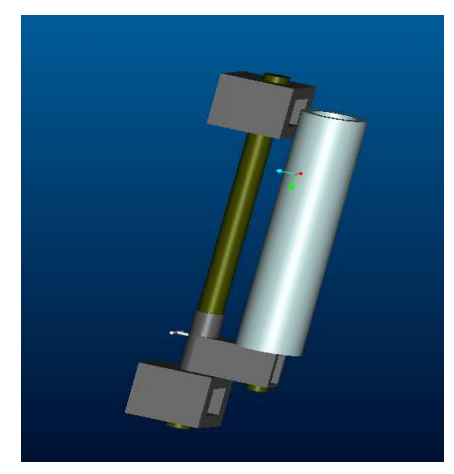

Fig 11. The fixed support for the tape 


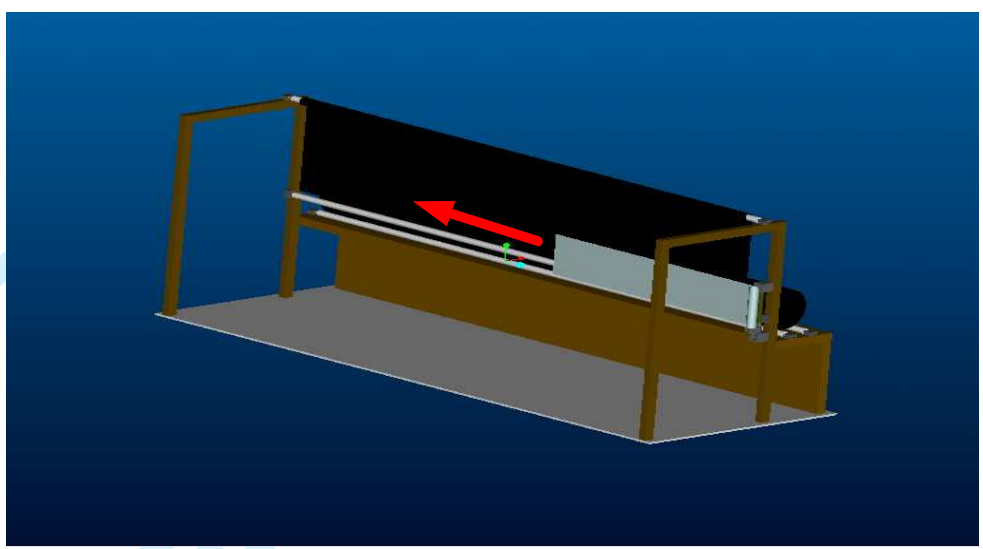

Fig 12. The implementation of the corrective action 


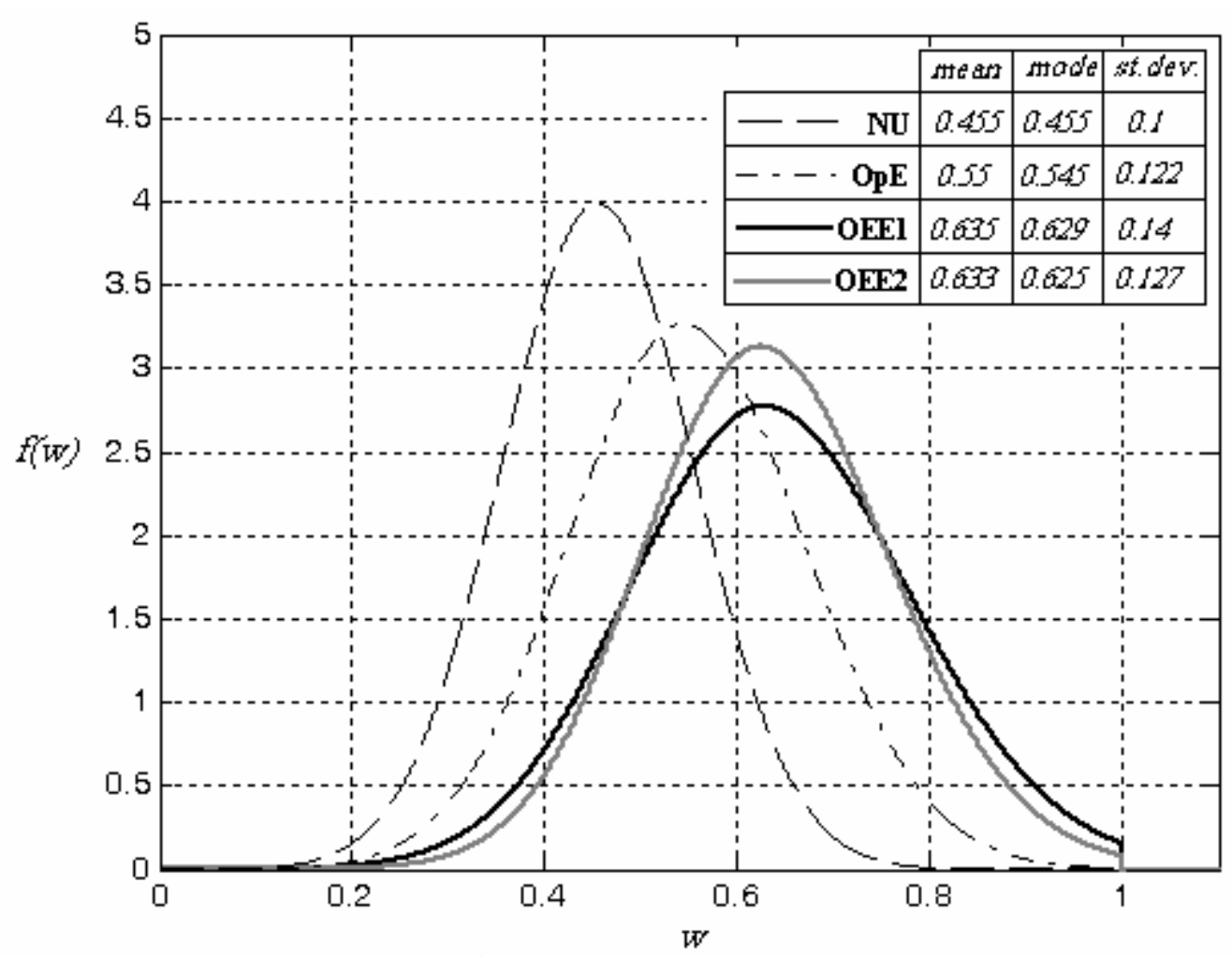

Figure 13. The effectiveness metrics of the equipment 


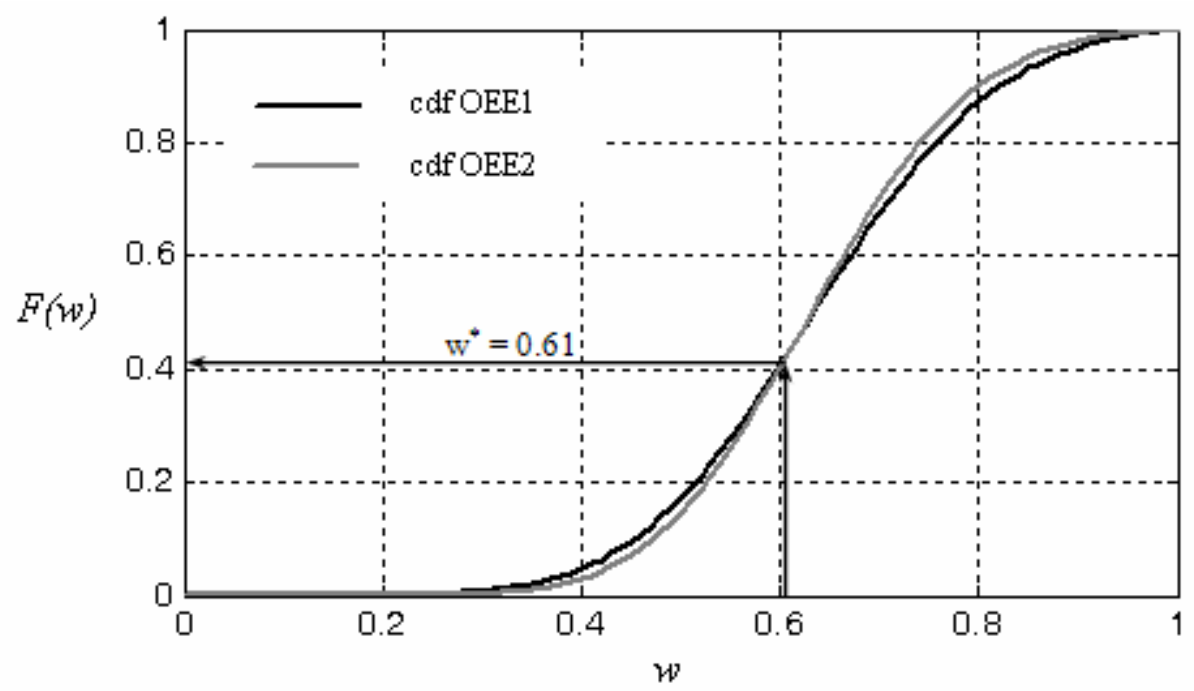

Figure 14. Comparison of the OEE before and after the corrective action 
Table 1. Time Losses of the equipment

\begin{tabular}{|c|c|c|c|}
\hline \multicolumn{2}{|c|}{ TIME LOSSES } & $\boldsymbol{\mu}[\mathbf{m i n}]$ & $\sigma[\mathbf{m i n}]$ \\
\hline \multirow{4}{*}{ NWT } & Strikes & 360 & 150 \\
\cline { 2 - 4 } & Stock Out & 120 & 60 \\
\cline { 2 - 4 } & Lack of demand & 245 & 120 \\
\cline { 2 - 4 } & Security Drillings & 80 & 20 \\
\hline \multirow{4}{*}{ SBT } & Planned Maintenance & 100 & 10 \\
\cline { 2 - 4 } & Blocking & 80 & 35 \\
\cline { 2 - 4 } & Micro Absenteeism & 280 & 140 \\
\cline { 2 - 4 } & Operators Transfers & 55 & 20 \\
\cline { 2 - 4 } & Lacking of Fork Lift & 28 & 20 \\
\hline \multirow{4}{*}{ DT } & On Line Quality Control & 11 & 1 \\
\cline { 2 - 4 } & Failures & 500 & 300 \\
\cline { 2 - 4 } & Change Over & 360 & 250 \\
\cline { 2 - 4 } PLT & Start Up & 80 & 30 \\
\cline { 2 - 4 } & Shut down & 25 & 15 \\
\cline { 2 - 4 } QRT & Micro Stoppage & 94 & 80 \\
\cline { 2 - 4 } & Reduced Speed & 115 & 50 \\
\cline { 2 - 4 } & Cleansing & 72 & 30 \\
\cline { 2 - 4 } & Defects & & 1 \\
\hline
\end{tabular}

